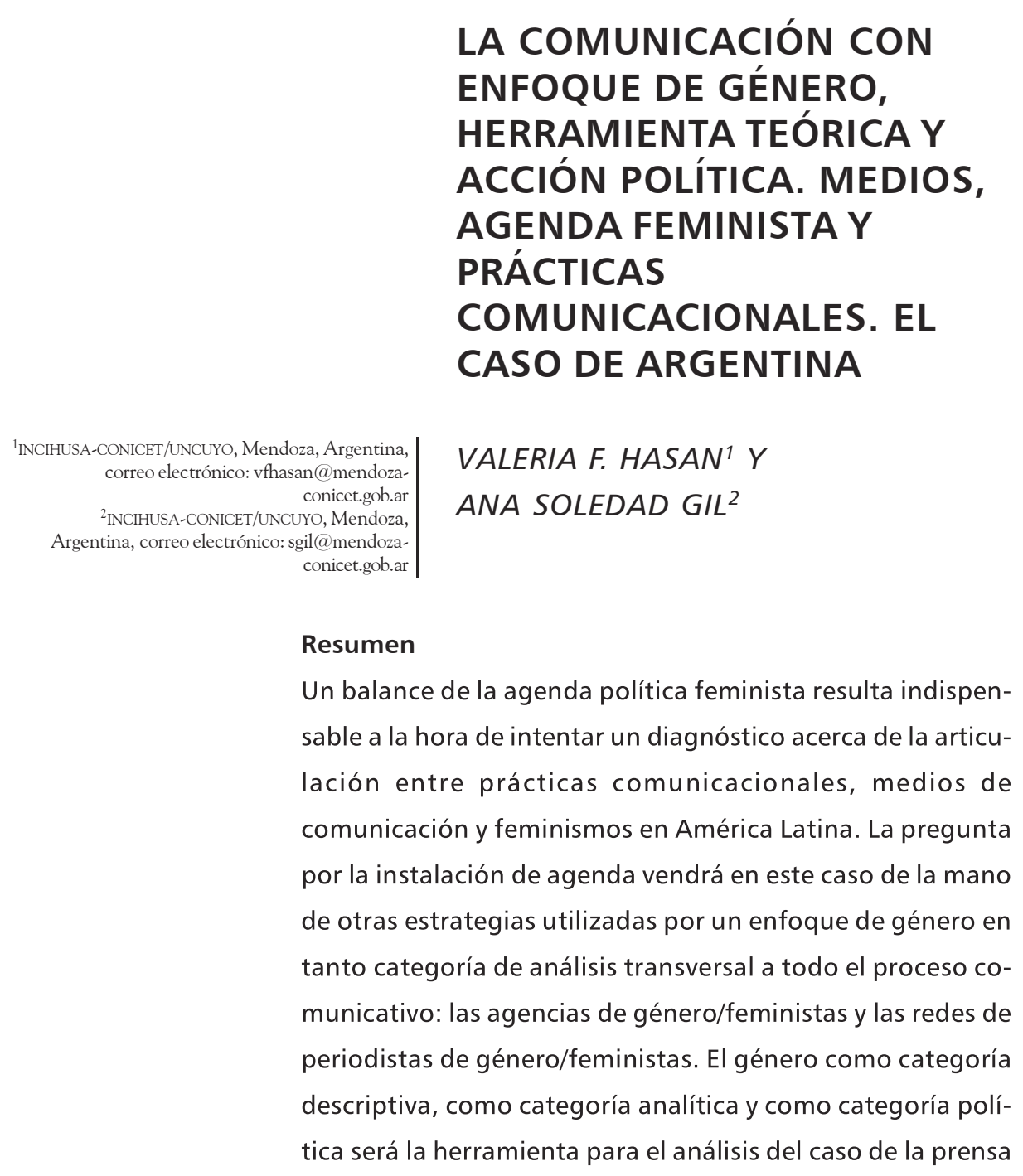


en Argentina donde haremos una especial mención al tratamiento de la violencia contra las mujeres.

Palabras clave: género, acción política, medios de comunicación, feminismos, agenda.

\begin{abstract}
A balance sheet of the political feminist agenda turns out to be indispensable at the moment of trying to find a diagnosis of the articulation between communication practices, mass media and feminism in Latin America. The question for the installation of an agenda will come by the hand of other strategies used by an approach of gender while category of transverse analysis to the whole communicative process: the agencies of gender/feminist and the journalist networks of gender/feminist. The gender as a descriptive category, as analytical category and as political category will be the tool for the analysis of the case of the press in Argentina, where we will do a special mention to the treatment of the violence against women.
\end{abstract}

Keywords: gender, political action, mass media, feminisms, agenda.

RECEPCIÓN: 29 de MARZO DE 2013 / ACEPTACIÓN: 05 DE AGOSTO DE 2015 
NUDOS DE DISPUTA EN LOS

FEMINISMOS LATINOAMERICANOS.

TEMAS DE AGENDA. DE LA POLÍTICA

\section{A LOS MEDIOS}

Un balance de la agenda de la política feminista latinoamericana es indispensable a la hora de intentar un diagnóstico que articule prácticas comunicacionales, medios de comunicación y feminismos en nuestra región. Las tensiones al interior del movimiento hacen concebir, en determinados momentos, incluso, en algunas de sus militantes, la idea de reformular el concepto mismo de movimiento, resignificándolo, o de buscar otro. Ximena Bustamante indica que

La retícula autonomía/institucionalización ha servido para articular un campo discursivo de acuerdo con el cual es posible trazar una nítida división entre quienes han sido cooptadas por el poder y quienes lo resisten. La división es planteada como el gran punto de quiebre político del feminismo latinoamericano (Bustamante, 2010: 172).

Aparece como contraparte la posibilidad de pensar el movimiento como momentos de acción colectiva, más que como un ente con existencia permanente. El punto de partida es el reconocimiento de la multiplicidad de los feminismos y sus 
agendas divergentes que no impediría períodos de acción colectiva y de alianzas. De este modo, el movimiento no sería algo que es, sino algo que tiene lugar, algo que acontece (Bustamante, 2010: 184).

En los años 1990, junto a la dramática dirección impuesta por el capitalismo tardío, se gestan los feminismos de fin de siglo. Dicho de otro modo, mientras el neoliberalismo se afianza e impone la idea de que el mundo es una aldea global, buena parte de nuestros países ve acrecentarse el desempleo, la desnutrición, el colapso de la educación y las denominadas reformas del Estado (en educación, en salud, en seguridad social, etcétera) bajo las directivas del Consenso de Washington. Las mujeres fueron las más afectadas por este giro de la economía dando origen a la expresión "feminización de la pobreza". Según Francesca Gargallo (2006) esto produjo una explosión de grupos de mujeres diversas, que sin enrolarse en el feminismo, se unieron creando distintas organizaciones de campesinas, pobladoras, pescadoras, trabajadoras, refugiadas, desplazadas por motivos ecológicos o políticos. Al mismo tiempo, las feministas empezaron a trabajar de manera especializada en los denominados temas de mujeres, y llegaron las tecnócratas del género, las "femócratas" (Fernández Hasan, 2012a).

Este es entonces el momento de eclosión de autónomas e institucionalistas. Momento en que surge en América Latina el fenómeno novedoso que significaron las ONGs y junto a ellas lo que se denominó feminismo institucional. Sonia Álvarez 
(1997) sostiene que el aumento de la demanda de instituciones extragubernamentales con información especializada sobre la situación de las mujeres se explica a través de dos razones. Por un lado, las instituciones dominantes incorporaron temas selectos relacionados con las mujeres a sus agendas. Por otro, se destaca la creación de instituciones gubernamentales e intergubernamentales que trataban la problemática de las mujeres, la proliferación de leyes específicas y otras formas de institucionalización de la agenda de transformación feminista. Las ONGS se presentaron como un mecanismo eficaz para la instrumentación de políticas públicas. En el extremo opuesto, las llamadas autónomas, son grupos o colectivos feministas que se corresponden con el molde fundacional de la militancia feminista. Según la visión de Álvarez, están integrados por participantes voluntarias, en general, a veces esporádicas, con estructuras de organización más informales, presupuestos de operación más bajos y acciones con metas coyunturales y quizás menos definidas. En palabras de Ximena Bustamante, en el viejo tablero político, cuando se hablaba de autonomía, el referente eran las organizaciones y partidos de izquierda.

A partir de 1990, las feministas autónomas empiezan a hablar de un enemigo amorfo denominado institucionalización, que incluye tanto la onegeización del movimiento (en el sentido de que el movimiento se estaba volviendo una ong de grandes proporciones), como los organismos internacionales y la creación de instancias gubernamentales dedicadas a di- 
señar políticas públicas con perspectiva de género (Bustamante, 2010).

Si bien en 1993 en el VI Encuentro Feminista Latinoamericano y de El Caribe (EFLAC) en El Salvador se evidenciaron las primeras controversias, fue en 1996, con motivo del VII EFLAC, en Cartagena, Chile, que se produjo la divisoria de aguas casi definitiva. Los temas dominantes en la reunión fueron autonomía e institucionalización, financiamiento y representatividad. Como lo señalan Carmen Teresa García y Magdalena Valdivieso (2005), las autónomas decidieron no participar basándose en su rechazo a todo lo institucional sustentado en el financiamiento externo. La discusión entre unas y otras trascendió el espacio de la militancia abarcando la academia, la política partidaria y las instancias internacionales. Las autónomas, consideraban que a partir de la institucionalización progresiva del feminismo dentro de los partidos políticos, las ONGs o las instituciones del Estado, el movimiento perdía el carácter libertario y subversivo propio de su origen, debilitando así, su fuerza. Las tensiones entre ambos grupos, lejos de ser superadas, volvieron a ser fuertemente visibilizadas en el XI EFLAC realizado en México, en 2009, donde hubo dos reuniones en forma parcialmente superpuesta, la "oficial" y la "autónoma". Por un lado, como señala Bustamante, quienes se denominan "autónomas" han trabajado o trabajan financiadas por diferentes organizaciones, en universidades, fundaciones y organismos internacionales. La clave para distinguirse parece ser la 
autoidentificación ya que explican su trabajo como necesario para la supervivencia y por fuera de estas instituciones. Otro eje de discusión está puesto en la inclusión, o no, de las transgénero como participantes de los EFLAC. En este caso, lo que subyace es la discusión en torno de las políticas de la identidad (Fernández Hasan, 2012a).

En pocas palabras, como señala Yuderkys Espinosa Miñoso, los nudos de disputa fundamentales que atraviesan el campo feminista ya no están en las polémicas coyunturales con un otro unificado y afuera,

Otro que nos ayuda a mantener intacta esa ficción de un nosotras compacto también. Se trata de una mirada compleja sobre el dentro, una mirada autoreflexiva, interna en la política feminista, una política viva ataviada de paradojas, tensiones, silencios y por qué no también, apuesta de esperanzas (Espinosa, 2011: 1).

Las feministas autónomas que impulsan estos procesos se declaran comprometidas con una lectura compleja de la realidad articulando autonomía a paradigmas teórico-políticos que proponen nuevas perspectivas y prácticas que enfrentan los regímenes coloniales y neocoloniales del género, la raza, la clase y la heterosexualidad. Al mismo tiempo problemáticas como la pobreza, el feminicidio, el etnocidio, la violencia, las políticas 
represivas, la militarización de la vida en las democracias liberales, el consumismo, la depredación y la usurpación de los territorios y recursos naturales de los pueblos ancestrales, conforman los temas de la agenda de este feminismo que se define como autónomo, crítico, contrahegemónico, decolonial y propositivo. En pocas palabras, núcleos fuertes como sexualidades, lesbianismo, homosexualidad, biodiversidad, trata y tráfico de mujeres y prostitución, sumados a los ya clásicos aborto, etnocentrismo y racismo son los temas de agenda de este feminismo contrahegemónico.

En tanto, las institucionalistas también poseen su agenda de temas prioritarios, emanada de lo consensuado por los organismos internacionales a partir de Beijing y algunos de sus documentos, Organización de las Naciones Unidas (ONU), Organización de los Estados Americanos (OEA), Programa de las Naciones Unidas para el Desarrollo (PNUD), redes regionales, comités, en el marco del debate del derecho internacional, los avances legales respecto de la ciudadanía de las mujeres y las deudas pendientes registradas en documentos y conferencias internacionales. Algunos de esos temas son: violencia contra las mujeres, feminicidio, justicia, desarrollo, equidad, derechos humanos de las mujeres, derechos económicos, sociales y culturales, derechos sexuales y reproductivos, despenalización del aborto, diversidad sexual, racismo y discriminación, participación política, desarrollo rural, defensa del medioambiente, paz, pobreza, edu- 
cación, migración, interculturalidad, publicidad sexista (Fernández Hasan, 2011).

La agenda feminista de la región, más allá de sus propios portavoces en portales, blogs y perfiles en redes sociales feministas o en medios contrahegemónicos, cuyo destinatario es preferencialmente el feminismo y sus aliados (colectivos que defienden causas cercanas como bienes comunes, movimientos antiglobalización, campesinos, antiminería, etcétera), ¿tiene algún eco en los medios de comunicación; sean estos impresos o digitales, tradicionales en sentido estricto o más innovadores por su formato, su estilo discursivo o su contrato de lectura?

Si como rezaba la mentada teoría de la agenda setting, lo que no ingresa a la agenda de los medios, no existe, pues para ocupar un lugar en el espacio público los feminismos, las mujeres, las diversidades sexuales, deben hacer su ingreso a la agenda de los medios para cobrar visibilidad social.

En este sentido, no deja de ser relevante para académicas y militantes revisar cómo es este ingreso de los temas urgentes del feminismo a la agenda de los medios. Si por un lado no podemos soslayar la mención a lo que consideramos una práctica disruptiva, al tiempo que motorizadora de un tipo de comunicación contrahegemónica, en la creación y desarrollo de las agencias feministas de noticias y las redes de periodistas de género, ni dejar de ver en los portales de noticias on line ejemplos válidos de contradiscursos feministas, donde agenda feminista y agenda de los medios encuentran un espacio de con- 
fluencia propicio para el refuerzo, la publicidad de ideas, el debate, cumpliendo no sólo con su rol de informar sino estableciendo agenda y militando la causa de las mujeres bajo formato periodístico, tampoco podemos rehuir el hecho de que en los medios de comunicación masivos la situación no ha variado demasiado en los últimos años a pesar de las recomendaciones, campañas e impulso de leyes. Desde 1995, cuando en la Conferencia Mundial de Mujeres en Beijing, se consideró a los medios de comunicación como una de las doce áreas prioritarias para lograr la paridad entre los géneros, el avance ha sido escaso. Algunas de las conclusiones del monitoreo global de medios de la WACC ${ }^{3}$, en septiembre de 2010 , señalan que:

${ }^{3}$ WACC, por sus siglas en inglés: Asociación Mundial para la Comunicación Cristiana.

- Se siguen construyendo noticias donde los hombres superan en número a las mujeres en casi todas las categorías ocupacionales.

- Como entrevistadas o como protagonistas de noticias, las mujeres permanecen en la categoría de personas "ordinarias", mientras que los hombres son ubicados como "expertos".

_Es doblemente probable que se mencionen las edades de los sujetos femeninos de las noticias en comparación con la mención de la edad de los masculinos. 
Al $18 \%$ de los sujetos femeninos de las noticias se lo presenta como víctimas mientras que sólo el $8 \%$ son masculinos.

Las secciones policiales (crímenes y violaciones) mencionan a mujeres en un $23 \%$ mientras que a varones lo hacen en un $9 \%$.

- A las mujeres se las identifica de acuerdo con su relación familiar cuatro veces más en comparación con los varones.

El $26 \%$ de las mujeres aparecen en fotografías en los diarios, en tanto que solamente el $17 \%$ de los varones aparece en imágenes en los mismos medios. Del total de las notas relevadas, sólo el $6 \%$ destacó temas sobre igualdad/desigualdad de género.

El $13 \%$ de todas las notas se centra específicamente en las mujeres y $46 \%$ refuerza los estereotipos de género, es decir, casi ocho veces más que las que cuestionan dichos estereotipos (6\%).

Para ilustrar el estado de situación tomaremos por caso el contexto argentino, lugar donde recientemente se han sancionado leyes que impulsan avances concretos en relación a los derechos de las mujeres. En respuesta a los compromisos asumidos en el marco del derecho internacional y ante el concierto de las naciones del mundo, Argentina sancionó la Ley 26485 De Protección Integral para prevenir, sancionar, y erradicar la 
violencia contra las mujeres, con la finalidad expresa, entre otros propósitos, de combatir los contenidos discriminatorios de los medios de comunicación. A pesar de que aparecen en la letra de la ley diferenciadas las definiciones de violencia física, simbólica, emocional, mediática, etcétera, la herramienta legal no tiene la posibilidad de sancionar la vulneración de los derechos por ella preservados. Se trata de una ley de protección que apunta al cambio simbólico y cultural, pero que no puede operar sobre quienes la infringen. Aparece sí, la posibilidad de que el articulado sobre violencia mediática llegue a efectivizarse en sanciones sobre quienes la transgreden, a partir de la sanción, en octubre del 2009, de la Ley 26522 de Servicios de Comunicación Audiovisual, conocida como Ley de Medios ${ }^{4}$. La nueva Ley de Medios menciona, específicamente, la necesidad de la equidad de género y el respeto a las mujeres en diversas partes de su texto 5 .

Entendemos que la dimensión simbólica incide, de manera lenta y por momentos indirecta, en la moral, las

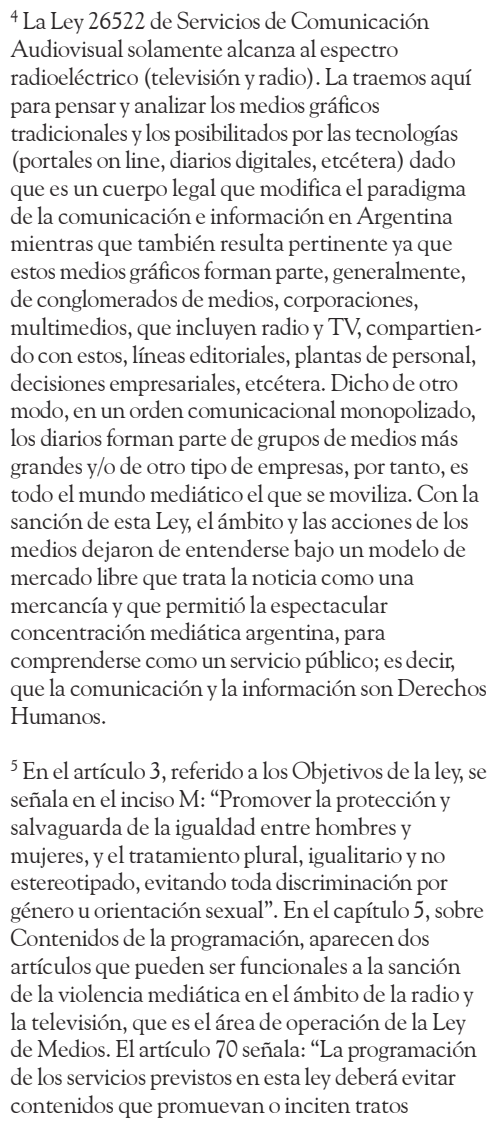

${ }^{5}$ En el artículo 3, referido a los Objetivos de la ley, se señala en el inciso M: "Promover la protección y

salvaguarda de la igualdad entre hombres y mujeres, y el tratamiento plural, igualitario y no estereotipado, evitando toda discriminación por género u orientación sexual". En el capítulo 5, sobre Contenidos de la programación, aparecen dos artículos que pueden ser funcionales a la sanción de la violencia mediática en el ámbito de la radio y la televisión, que es el área de operación de la Ley de Medios. El artículo 70 señala: "La programación de los servicios previstos en esta ley deberá evitar contenidos que promuevan o inciten tratos 
discriminatorios basados en la raza, el color, el sexo, la orientación sexual, el idioma, la religión, las opiniones políticas o de cualquier otra índole, el origen nacional o social, la posición económica, el nacimiento, el aspecto físico, la presencia de discapacidades o que menoscaben la dignidad humana o induzcan a comportamientos perjudiciales para el ambiente o para la salud de las personas y la integridad de los niños, niñas o adolescentes". En el 71 se especifican las leyes que deberán contemplar quienes controlen que los medios no vulneren la nueva Ley: "Quienes produzcan, distribuyan, emitan o de cualquier forma obtengan beneficios por la transmisión de programas y/o publicidad velarán por el cumplimiento de lo dispuesto por las leyes 23.344, sobre publicidad de tabacos; 24.788 — Ley Nacional

de lucha contra el Alcoholismo—; 25.280, por la que se aprueba la Convención Interamericana para

la eliminación de todas las formas de discriminación contra las personas con discapacidad; 25.926, sobre pautas para la difusión de temas vinculados con la salud; 26.485 —-Ley de protección integral para prevenir, sancionar y erradicar la violencia contra las mujeres en los ámbitos en que desarrollen sus relaciones interpersonales_-; 26.061, sobre protección integral de los derechos de

las niñas, niños y adolescentes así como de sus normas complementarias y/o modificatorias y de las normas que se dicten para la protección de la salud y de protección ante conductas discriminatorias".

En el capítulo 8, referido a la Publicidad, se señala en el inciso i: "Los avisos publicitarios no importarán discriminaciones de raza, etnia, género, orientación sexual, ideológicos, socio-económicos o nacionali-

dad, entre otros; no menoscabarán la dignidad

humana, no ofenderán convicciones morales o

religiosas, no inducirán a comportamientos

perjudiciales para el ambiente o la salud física y moral de los niños, niñas y adolescentes. costumbres, el sentido común compartido y el substrato prejuicioso del que emanan las violencias y la discriminación contra las mujeres. Es por eso que la reforma de las leyes y la introducción de un lenguaje más preciso, adecuado y la expansión permanente de un sistema de nombres para cada situación, proceso social en ciernes, es un procedimiento imprescindible y fundamental.

La nueva ley de violencia de género, y las dimensiones de sentido que instala, al referirse por primera vez a la violencia simbólica como sostén del patriarcado, y la violencia mediática como uno de sus brazos más eficaces, probablemente marquen un hito en la problematización del sexismo hacia las mujeres en los medios de comunicación.

DE AGENCIAS Y REDES: PRÁCTICAS COMUNICACIONALES ESTRATÉGICAS La articulación entre los grupos de mujeres, las feministas y el impulso que en los años 90 's tuvieron 
los derechos para las mujeres, se fue dando paulatinamente a medida que la década fue avanzando. Los primeros datos sistematizados datan de 1993 con la creación del programa APC-Mujeres en Ecuador, con la intención de acercar las redes sociales de mujeres a las redes electrónicas ante la IV Conferencia Mundial en Beijing, dando origen a las primeras redes de mujeres en Internet (Boix, 2001). A partir de allí se multiplicaron los foros de debate, las listas de correo (Modemmujer, RIMA), portales informativos, sitios de diferentes colectivas, y más tarde, agencias de noticias, blogs, revistas, radios on line, periódicos feministas, redes sociales con perfiles de periodistas especializadas, todo un universo se desarrolló exponencialmente a la par del crecimiento veloz e inasible de la web en las dos últimas décadas.

Como anticipamos más arriba, es relevante en la instalación de agenda el rol desempañado por las agencias de género como el caso de Semlac (agencia regional en América Latina y el Caribe), que resultaron una clara alternativa al modelo de información hegemónico. Como indica Cristina Fraga, las agencias de noticias funcionan como el lugar para la "construcción de un periodismo no sexista y visibilizador de las mujeres, las grandes ausentes del discurso informativo" (Fraga, 2004: 1). En este sentido, las agencias feministas de noticias muestran realidades ocultas para el resto de las agencias. Junto a las agencias feministas de formato tradicional, de búsqueda y construcción de noticias, desarrollan tareas a la manera de 
agencias de género las actividades individuales de las periodistas que construyen su información dando voz a quien no la tiene, poniendo en cuestión los prejuicios y las brechas de género, estableciendo redes informales de comunicación con otras colegas (Fraga, 2004). Una tercera modalidad de agencia de género es la reflexión teórica y crítica sobre el discurso informativo de los medios de comunicación que realizan y producen las feministas académicas, que luego es retomado y replicado tanto por las agencias en sentido estricto como por los medios de comunicación feministas y/o de género y por las periodistas feministas que cumplen funciones en medios tradicionales y aprovechan ciertas grietas para hacer circular información con perspectiva de género producida en la academia en tanto posee el aval emanado por la "ciencia". También operan como agencias de género los portales con contenidos específicos, propios de la agenda de género (violencia, aborto, feminicidio, trata, etcétera), que las colectivas de mujeres impulsan con el objetivo de instalar y debatir al interior del movimiento y con el resto de la sociedad, dos de ellas sirvan como ilustración: Mujeres Creando, de Bolivia e Isis Internacional. En los últimos tiempos, se han sumado, los perfiles de periodistas y académicas en las redes sociales y los blogs, sitios ambos que aportan información que se propaga por fuera de los grandes medios, suele alimentarlos y cumple sin dudas, función de agenda. 
El paradigma de la agencia de noticias con perspectiva de género o feminista en América Latina es, sin dudas, Cimacnoticias. Según relata Sara Lovera, en 1995, Comunicación e Información de la Mujer Asociación Civil (CIMAC), se organizó como una mesa de redacción de los temas de las mujeres. Sus primeras acciones se redujeron a promover las campañas del movimiento feminista internacional y algunos temas coyunturales de México: cubrir el 8 de marzo, la campaña del 28 de mayo, el 25 de noviembre, hasta finalmente sumar el resto de las fechas de la agenda feminista (Lovera, 2004: 26). Hoy Cimacnoticias es una agencia de información multimedia que produce y distribuye información escrita, un paquete semanal de reportajes y artículos, en envíos diarios y semanales para 2308 suscriptoras/es, alimenta de información a más de 30 periódicos mexicanos, estatales, regionales y diversos portales de información internacional. Su portal tiene 35 mil visitas diarias en promedio. Se maneja con convenios firmados con otras agencias de información como Reuters y ocupa un lugar de consideración entre las voces autorizadas a chequear por los medios mexicanos y centroamericanos a la hora de establecer su agenda. Como muestra Lovera, "se trata de competir profesionalmente, ello sin perder la perspectiva feminista y de género" (2004: 31).

En Argentina, el paradigma de las agencias de género fue Artemisa Noticias. Con cobertura nacional diaria a través de corresponsalías internas, Artemisa nació en 2005 y en abril 
de 2012, la agencia como tal se despidió después de casi siete años de trabajo de comunicación no sexista. Una parte del equipo encaró un nuevo proyecto bajo el nombre Comunicación para la igualdad con portal y perfil en Facebook (Comunicar lgualdad) bajo el liderazgo de la periodista Sandra Chaher, una de las dos fundadoras de Artemisa.

Algunas de las tareas que Artemisa Noticias desarrolló en los años en que estuvo vigente fue la cobertura de noticias, diariamente, a través de su portal (que actualmente permanece on line con toda su producción disponible), la capacitación de comunicadoras/es, periodistas y funcionarias/os de áreas de comunicación de Argentina y América Latina, la promoción de la creación y armado de redes de periodistas en Argentina, América Latina y el resto del mundo, monitoreo de medios sobre temas puntuales como aborto, la presentación de la agenda mediática de género y el protocolo de tratamiento de los temas para trabajar en los medios de comunicación (en colaboración con periodistas e integrantes de organizaciones no gubernamentales), publicación de libros y revistas.

Junto al fenómeno de las agencias de noticias, a principios de 1990, comienzan a aparecer las primeras redes de periodistas con visión de género, como otra forma de asociación, vinculada a la anterior. Estas redes agrupan a mujeres y a algunos varones solidarizados con la causa, insertos tanto en medios masivos como alternativos, y también en agencias de noticias de género. 
El sentido más fuerte de la creación de estas agrupaciones fue compartir la experiencia de una tarea no valorada en los medios, pero considerada indispensable por quienes estaban fundando estas redes y, a la vez, generar un espacio de incidencia sobre los medios masivos y sobre las agendas públicas, acompañando la agenda política del movimiento feminista (Chaher, 2010).

Las redes de comunicación de género se ocuparon especialmente de destacar a las mujeres como sujetos de la información y la comunicación, sumándolas de este modo a la crítica por la explotación de las mujeres como objetos, en tanto imágenes o discursos circulantes por los medios. Esto se tradujo en una atención puesta sobre las periodistas en sus lugares de trabajo, su presencia en los medios, como profesionales de la comunicación, directoras, fuentes de opinión, modalidades de trabajo, dificultades, estrategias, y además, interés también y al mismo tiempo, por los diversos ámbitos de la comunicación desde una perspectiva de incidencia de las mujeres, su acceso a la expresión y su capacidad de propuesta y presión (Fernández Hasan, 2012b).

En el caso latinoamericano, a partir de 1995, CIMAC impulsó la creación de las primeras redes nacionales en América Latina dando origen a la Red Nacional de Periodistas de México. Le siguió la Red de Mujeres Periodistas de Guatemala en 1998, la Red Dominicana de Periodistas con Visión de Género en 2001y la Red de Mujeres Periodistas de Nicaragua en 2003. 
La Red Nacional de Mujeres Periodistas de Perú nació en 2008 y la Red Colombiana de Periodistas con Visión de Género en 2009.

Para el caso argentino, las más relevantes: en 2006, Periodistas de Argentina en Red-Por un periodismo no sexista (PAR) cuya acción pública más resonante en sus orígenes fue la elaboración, a principios de 2008, del Primer Decálogo Argentino para el Tratamiento periodístico de la violencia contra la Mujer y su participación en la Red Internacional de Periodistas con Visión de Género (RIPVG) que integran, desde 2005, periodistas y comunicadoras de América y Europa.

Entre 2008 y 2009 en Artemisa Comunicación se desarrolló el proyecto Agenda Mediática de Género. El objetivo fue vincular a periodistas especializadas/os y representantes de organizaciones no gubernamentales para establecer una agenda de temas de género a ser tratados en los medios de comunicación. El resultado fue el diseño de un Protocolo de tratamiento de los temas de género y una agenda de trece temas a ser abordados por los medios. Sobre tres, de estos trece, se estableció un trato

${ }^{6}$ Los otros diez fueron: ciudadanía y acceso a la justicia; deporte, tiempo libre y ocio; educación; hábitat, ambiente y ciudad; medios de comunicación; niñez y vejez; pobreza y exclusión; salud (con énfasis en VIH/Sida que continúa invisivilizado y cuya feminización crece cada año); sexualidad y diversidad sexual; trabajo productivo y
reproductivo. preferencial ya que se entendió que en ellos se iba la vida de las mujeres: derechos sexuales y reproductivos, trata de personas y violencia de género ${ }^{6}$. Esta agenda consensuada está en consonancia con la agenda feminista reforzándose mutuamente a lo largo del continente. 
En septiembre de 2009, una de las conclusiones del Iv Encuentro Nacional de la Red PAR, fue proponer como estrategia de incidencia periodística la visibilización de la violencia de género focalizada en el feminicidio, el aborto y la trata de personas para explotación sexual. En noviembre de ese año, una de las conclusiones del III Encuentro de la RIPVG, con periodistas de diecisiete países reunidos en Bogotá, fue el acuerdo en privilegiar cuatro temas en el tratamiento periodístico: violencia de género y feminicidios, trata de personas, derechos sexuales y reproductivos y situación de las mujeres en países en conflicto armado con una perspectiva de paz y no violencia (Chaher, 2010: 135-139).

EL INGRESO A LA AGENDA

MEDIÁTICA EN ARGENTINA

Un relevo por los principales medios argentinos, tanto tradicionales como los posibilitados por las tecnologías de la información, muestra rápidamente cómo los temas propuestos para ser instalados por la agenda feminista, en consonancia con la agenda de las redes de periodistas feministas y/o de género, efectivamente lograron en los últimos años ingresar a la agenda de los medios. Sin embargo, un ojo aguzado debe advertir la manera en que lo hicieron. Por ejemplo, desde diciembre de 2012 a la fecha, el diario Clarín, el matutino de mayor tirada nacional y uno de los multimedios actuales más grandes y concentrados, ha publi- 
cado alrededor de 10 títulos sobre Trata de personas. Estos son algunos de ellos: "La trata de personas no es un problema acotado a una región sino que afecta a todo el país", "Amnistía Internacional pidió que "no quede impune" el caso Marita Verón", "Rescatan a cuatro mujeres que eran víctimas de una red de trata en Monserrat".

Por el lado de los derechos sexuales y reproductivos, el tema de mayor visibilidad e impacto mediático ha sido, sin duda, el aborto. El diario La Nación, identificado con los valores más tradicionales y conservadores de los sectores dominantes en Argentina, publicó alrededor de 15 títulos desde octubre de 2012 a la fecha. Estos son algunos: "Macri vetó la ley de aborto no punible", "Aborto: dos marchas, a favor y en contra, chocaron en Plaza de Mayo", "Uruguay privilegió la muerte", "Los obispos españoles aceptaron el uso de la "píldora del día después".

Finalmente, algo similar ocurre con la problemática de la violencia de género, cuestión que ha cobrado una hipervisibilización en los medios tradicionales. En el presente trabajo focalizamos sobre esto al ir más allá de la aparición de estas situaciones en los medios de comunicación, e intentar presentar un panorama sobre cómo es el tratamiento que reciben estas noticias.

Sólo en el mes de marzo de 2013, el diario Clarín publicó cerca de 10 títulos bajo la etiqueta "violencia de género". Algunos de ellos son: "Córdoba: un policía mató a su mujer 
delante de su hijo de 4 años", "Viedma: ${ }^{7}$ Las notas pueden consultarse en: http:// una policía fue asesinada por su ex

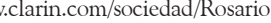
violencia de generomujer asesinada 0 889711187.html http://www.clarin.com/sociedad/Viedma-policiaasesinada-frente-colegio_0_889111273.html http://www.clarin.com/sociedad/Cordobaviolencia_de_generoesposo frente al colegio de sus hijos", "Rosario: discutió con su mujer y la mató de un escopetazo"7. Mientras que policia_mato_a_su_mujer_0_889111200.html

el diario La Nación publicó 3 títulos en el mes de marzo y 12 en el mes de febrero del corriente, con la misma designación. Algunos de ellos son: "Procesan a un hombre que asesinó a su mujer de 43 puñaladas", "Asesinan a una joven en un hotel de Córdoba", "Mató a su amante en una escuela y luego se suicidó"8.

Si bien en todas estas noticias encontramos en diferentes partes (volantas, títulos, copetes, cuerpo) términos como "violencia de género", "violencia contra la mujer" o "femicidio", el tratamiento periodístico recae en una serie de sentidos comunes y estereotipos de género que, finalmente, no contribuyen a modificar la estructura de las relaciones desiguales de género que posibilitan que estas situaciones sucedan casi a diario. En otras palabras, las construcciones de las noticias relativas a violencia contra las mujeres o violencia de género han alcanzado en los últimos tiempos una mejora en cuanto a que la problemática ha ingresado a la agenda política y una mayor visibilidad social. No obstante, el hecho de que títulos como "crimen pasional" o "amores que matan" casi hayan desaparecido de los medios 
no ha venido acompañado de una mejora en el tratamiento de las noticias. Éstas se siguen construyendo en torno del imaginario del amor romántico y la pasividad erótica para las mujeres mientras que la violencia encuentra atenuantes en los celos, la traición, la infidelidad, el desacato, la desobediencia al orden establecido.

Las tres notas mencionadas de Clarín, son cortas y sólo apelan a fuentes policiales construyendo la información desde el hecho policíaco. No hay referencias a los derechos humanos de las mujeres, ni a las estructuras patriarcales que habilitan la violencia de género. Tampoco se publica información para concientizar a la sociedad y se buscan razones como "fuertes discusiones", "separaciones", "infidelidad de la mujer".

Sobre las notas mencionadas de La Nación, el tratamiento es similar al de Clarín. En algunas, se especifica con gran detenimiento el asesinato y en otras las "relaciones sentimentales" dejando entrever amarillismo y sensacionalismo. Es de destacar que una de las notas comienza con la volanta "Violencia de género" mientras que en el primer párrafo habla de "drama pasional". Esto resulta una contradicción dado que, todas las recomendaciones nacionales e internacionales para el tratamiento mediático y periodístico de la violencia de género, establecen que estas muertes nada tienen que ver con la pasión sino que se enmarcan en una violación a los derechos humanos de las mujeres. En general, también las situaciones se presentan aisladas unas de otras, como meros casos policiales. 
La importancia de comprender las consecuencias que conllevan un tratamiento mediático de las mujeres, sus temas y problemas, desde el sexismo y la discriminación radica en que el periodismo y los medios en general, producen sentido social y/o, en términos de Gramsci (1971), sentido común. Esto es, como empresas de la información, los medios de comunicación, se encuentran insertos en la lucha por el sentido. Son instituciones culturales que construyen y producen determinadas formas de ver el mundo y de valorarlo. Los estereotipos de género atraviesan nuestras representaciones y prácticas de forma continua. En palabras de Bourdieu (2003), la naturalización de los significados de género parece dar cuenta del eficaz trabajo que a lo largo de la historia fueron afinando, instituciones sociales como la familia, la iglesia, el Estado, y por supuesto, los medios de comunicación.

Desde un punto de género, la violencia contra las mujeres debe ser comprendida como parte constitutiva de un sistema patriarcal que apela a ella para poder perpetuarse. De hecho, la legitimidad que aún tiene la violencia contra las mujeres es posible, en parte, por los discursos que circulan en la sociedad.

La violencia de género no sólo es una forma de perpetuación del poder patriarcal sino que, además, es necesaria para mantenerlo. Cuando un orden social como el nuestro se sustenta en el dominio de las mujeres por parte de los varones, la violencia contra las mujeres es una herramienta que resulta 
eficaz para mantener ese poder dominante que se transmite de generación en generación, a través de valores, formas de ver el mundo, estereotipos y normas (Gil, 2012).

En sí, el ejercicio de la violencia resulta una estrategia habitual de dominación de quienes ejercen el poder en un determinado sistema socio-histórico. La antropóloga Rita Segato señala que la violencia cruenta no es un arrebato sin sentido, sino que, por el contrario, tiene un fin disciplinador y vengador contra las mujeres. Es un acto que busca castigar a aquellas que se rebelan contra el orden hegemónico tradicional. Dice Segato, "el desacato de esa mujer genérica, individuo moderno, ciudadana autónoma, castra al violador, que restaura el poder masculino y su moral viril en el sistema colocándola en su lugar relativo mediante el acto criminal que comete" (2003: 139). Desde este punto de vista, la violencia de género requiere de un efectivo consenso social para existir y perdurar. El silencio y/o las complicidades entre actores e instituciones profundamente patriarcales, entre ellos los medios tradicionales de comunicación, son fundamentales en este proceso. Por tanto, se hace necesario considerar la cuestión de la violencia simbólica y mediática ya que, sin el control del campo simbólico cultural, la violencia cruenta no sería legitimada (Gil, 2012). 


\section{COMUNICACIÓN CON ENFOQUE}

DE GÉNERO

En consonancia con el tratamiento adecuado de los

temas urgentes de la agenda feminista (violencia, aborto, feminicidio), en los últimos años se ha visto el desarrollo de vasta bibliografía relativa a comunicación con enfoque de género. Diferentes colectivas de mujeres, agrupaciones feministas, periodistas con visión de género y comunicólogas especialistas en género han desarrollado diversos materiales en relación a la comunicación con enfoque o perspectiva de género, destinada, fundamentalmente pero no de manera excluyente, a periodistas insertos/as en los medios masivos de comunicación. A grandes rasgos la comunicación con enfoque de género no es simplemente escribir, informar ni hablar sólo sobre mujeres. Se trata de entender el género como categoría de análisis transversal en todo el proceso comunicativo; es decir, que toda la información, la totalidad de los temas en las diferentes secciones, sean tratados con perspectiva de género. En este marco, puede entenderse la distinción entre el género como categoría descriptiva, donde se visibilizan las desigualdades entre hombres y mujeres; el género como categoría analítica que permite interpretar estas desigualdades y el género como categoría política que posibilita entender las formas de distribución de poder entre los géneros, y en consecuencia, la discriminación y subordinación de las mujeres en la sociedad. 
Algunas de las recomendaciones más socializadas para una comunicación con enfoque de género son aquellas referidas a un tipo de producción atenta a desnaturalizar los supuestos tradicionales del periodismo más conservador de tipo liberal, con sus estandartes de objetividad, prensa amarilla y construcción de la noticia con un varón siempre sujeto de la acción, informante clave, especialista, protagonista de la noticia o referente único.

Un listado de sugerencias para un periodismo de género/ feminista contempla:

- Establecimiento de temas prioritarios en consonancia con la agenda feminista (los llamados temas urgentes; es decir, violencia/femicidio, trata/ explotación sexual, derechos sexuales y reproductivos/aborto) acompañados de otros temas de coyuntura

- Mantenimiento de estos temas en la agenda.

- Contextualización de las noticias esquivando a un tratamiento del tipo "caso".

Fuentes de información donde las mujeres sean consultadas prioritariamente como voces autorizadas.

Estadísticas de género.

- Visibilización de logros y valores de ambos sexos en la construcción de las noticias. 
_ Análisis de cómo afecta determinada situación a mujeres y varones.

- Presencia equilibrada de ambos sexos en el relato.

_ Énfasis en la participación y aportes de las mujeres que se hayan destacado en los diferentes campos. - Opiniones de las mujeres en los análisis.

Cuidado de destacar o visibilizar fracasos o errores cometidos por una mujer y minimizar errores o fracasos semejantes, protagonizados por varones.

- Reflejo como deseable y propio para todos/as de cualidades como ternura, compasión, fuerza, dignidad, autoridad, seguridad, valentía.

- Selección y uso de imágenes y musicalización que terminen de construir la noticia en el marco de una perspectiva de género y por fuera del género rojo o amarillo.

- Atención a las dobles o triples discriminaciones de algunos colectivos, como los de género/etnia/clase/nacionalidad/edad.

Un tópico aparte es el referido al cuidado especial del uso sexista y racista del lenguaje. En este último caso, utilizar un lenguaje incluyente es adaptarlo a las realidades político-sociales de un mundo en transformación y, a su vez, contribuir a las transformaciones sociales que aspiran a un mundo más 
justo e igualitario. El lenguaje mismo es una herramienta de cambio. En el lenguaje se revelan valores y se evidencian las relaciones de poder existentes, dando voz o silenciando, nombrando u ocultando. En este sentido, el lenguaje es fundamental para construir modelos de identificación positivos y negativos, con lo cual tanto los estereotipos de género como la discriminación y la violencia de género se producen y reproducen constantemente, también, a través de las palabras que se usan y de las que se omiten.

Actualmente las sugerencias más destacadas en relación a un lenguaje no sexista comienzan desnaturalizando la ficción del masculino genérico proponiendo evitarlo, recurriendo a estrategias como la neutralización; es decir, utilizando térmi-

${ }^{9}$ Decir niños y niñas o madres y padres no es una repetición, no es duplicar el lenguaje. Duplicar es hacer una copia igual a otra y éste no es el caso. La diferencia sexual está ya dada, no es la lengua quien la crea. Lo que debe hacer el lenguaje es nombrarla, simplemente nombrarla puesto que existe. No nombrar esta diferencia es no respetar el derecho a la existencia y a la representación de esa
existencia en el lenguaje. No se trata de repetir todas las palabras de la frase con flexión de género, sino de duplicar por lo menos en una ocasión las palabras que aluden a mujeres y hombres para que amb@s estén explícitamente mencionados y sean visibles en la representación mental que se hace de nos genéricos y neutros que no marquen el sexo, como por ejemplo en alumnado, fiscalía, el personal docente; o la especificación, explicitando el sexo concreto de la persona a la que se hace referencia, incorporando los dos géneros en caso de referirse a personas de ambos sexos, mediante duplicaciones, barras, arrobas (las niñas y niños, firma del/a interesada/o, bienvenid@9 ${ }^{9}$.

Algunas palabras tenían, hace décadas, género común (es decir, eran invariables y la marca de género/sexo radicaba 
únicamente en el artículo que las precedían) como "el jefe" o "la jefe", o "el/la presidente", "el/la teniente", "el/la juez", "el/la ministro", "el/la fiscal". Hoy, en cambio, se feminizan visibilizando a las mujeres: la presidenta, la jueza, la ministra.

\section{CONSIDERACIONES FINALES}

Entendemos que la incidencia en la agenda pública por parte de periodistas, comunicadores/as, militantes sociales, movimientos sociales, como en el caso de PAR, resulta una práctica política que conlleva un potencial disruptivo, casi revolucionario en el seno de los medios tradicionales. EI punto de mayor puja se encuentra en el cruce de estas acciones con los intereses estructurales de los medios hegemónicos de comunicación, ya que de lo que se trata es de disputar el poder en el plano simbólico; es decir, de dar lucha por los sentidos a construir para acabar con un modelo de violencia estructural que se lleva la vida de las mujeres y de poder de cambio real, estructural, en un sentido amplio, de un orden establecido del mundo.

En todo este proceso de avances legales, la participación de los movimientos feministas y de mujeres resulta fundamental. En este orden, en Argentina y en el ámbito de la comunicación, la Red PAR ha desempeñado un importante rol. Tal como sostienen sus periodistas en el Decálogo para el tratamiento periodístico de la violencia contra las mujeres (versión 2010), "desde sus inicios, PAR propició la articulación 
con otras organizaciones de la sociedad civil, con los movimientos de mujeres y con las redes feministas locales, nacionales e internacionales, para incidir en la agenda periodística de los medios de comunicación" (PAR, 2010: 5).

Los medios propician determinados espacios a través de los cuales las feministas cuelan sus demandas, utilizando diversas estrategias. La articulación en redes y la construcción de noticias con enfoque de género es una más. Sin embargo, quedan aún muchas deudas por saldar. Los estereotipos más tradicionales insisten férreamente en permanecer bajo diferentes discursos o representaciones generando violencia mediática bajo variados ropajes. Así, la maternidad como motivo excluyente de realización personal continúa vigente tanto como la mujer protectora y conciliadora contrapuesta al varón audaz y con agallas. La mujer ama de casa, dependiente económicamente viene asociada a imágenes de limpieza, cocina, vida doméstica, en oposición a hombres de trabajo en la vida pública. La mujer vampireza, cazadora de hombres o maridos, aparece remanidamente en textos de toda índole, desde comedias familiares hasta publicidades de electrodomésticos. Suele asociarse también a la mujer consumista, que se dedica a gastar lo que el marido le provee. No faltan la banal, superficial, inestable emocionalmente, la mujer objeto sexual, cosificada y segmentada, simbólica y representacionalmente.

Por otro lado, en lo que se refiere a las trabajadoras de los medios, el informe Indicadores de Género para Medios de 
Comunicación que la UNESCO compiló en 2014, junto con la Federación Internacional de Periodistas, señala que los hombres ocupan la gran mayoría de los cargos directivos y gerenciales de los medios en las siete regiones del mundo $(74,1$ y $72,7 \%$ respectivamente); y que la imagen que se presenta en las noticias sigue siendo predominantemente masculina. Así, las representaciones, las voces y los discursos autorizados son mayoritariamente masculinos (76\%). En cuanto a las mujeres, aparecen prioritariamente en temas relacionados con crímenes, violencia, celebridades y entretenimiento (Fernández Camacho, 2015).

En el caso puntual del último relevamiento del Proyecto de Monitoreo Global de Medios (GPMMP) en 2010, para el caso de Latinoamérica, el porcentaje de mujeres que figuran en las noticias en la región era del $32 \%$ en televisión, $29 \%$ en prensa gráfica y $22 \%$ en radio. Sólo el $36 \%$ del periodismo entrevistado, en cada país y en las organizaciones mediáticas, eran mujeres. En términos de representación, la presencia femenina en las noticias está, fundamentalmente, relacionada con roles asociados a lo femenino tradicional, como los concursos de belleza. "La imagen de la mujer en los medios de comunicación latinoamericanos está básicamente relacionada con el rol estereotípico de la mujer en la familia, una situación que puede entorpecer la conceptualización de la mujer como individuo autosuficiente e independiente" (UNESCO, 2014: 142). 
Como hemos podido ver, es la lucha por los sentidos lo que está en juego. Batallamos por las formas, el lenguaje, las voces en disputa, las palabras puestas en discurso. Sin embargo, es más profunda la contienda, es el orden establecido del mundo lo que estamos transformando.

\section{| Bibliografía}

Álvarez, Sonia (1997). "Articulación y transnacionalización de los feminismos latinoamericanos", en Debate feminista, año 8, Vol. 15.

Boıx, Montserrat (2001). "La comunicación como aliada: Tejiendo redes de mujeres", en El viaje de las internautas. Madrid: Ameco. En línea. Disponible en http://www.nodo50.org/ameco/Tejiendo_redes _de_mujeres.pdf

BouRdieu, Pierre (2003). La dominación masculina. Barcelona: Anagrama. Bustamante, Ximena (2010). "Del XI eflac y otros demonios", en Debate feminista, año 21, vol. 41.

ChAER, Sandra (2010). "El camino hacia la paridad en los medios", en Las palabras tienen sexo II. Herramientas para un periodismo de género. Buenos Aires: Artemisa.

EsPinosa Miñoso, Yuderkys (2011). La política sexual radical autónoma, sus debates internos y su crítica a la ideología de la diversidad sexual. Grupo Latinoamericano de Estudios Formación y Acción Feminista (GLefAS).

Fernández CAMACHo, Mariana (2015). "Es fundamental transformar los discursos para fortalecer la autonomía de las mujeres y su protagonismo 
en la sociedad", en Comunicar Igualdad. En línea. Disponible en http://www.comunicarigualdad.com.ar/es-fundamental-transformarlos-discursos-para-fortalecer-la-autonomia-de-las-mujeres-y-suprotagonismo-en-la-sociedad/

FERNÁNDEZ HASAN, Valeria (2012a). “Una lectura de las agendas latinoamericanas del feminismo académico y de la política feminista. Género y experiencia como categorías fundantes", en II Foro Nacional Interdisciplinario "Mujeres en Ciencia, Tecnología y Sociedad, CNEA, CONICET, Bariloche.

(2012b). "Periodismo feminista en la web y estrategias en el uso de las TICs: construcción de agenda y producciones contradiscursivas", en Actas III Jornadas Internacionales de Problemas Latinoamericanos "Movimientos Sociales, Estados y Partidos Políticos en América Latina: (re)configuraciones institucionales, experiencias de organización y resistencia". UNCuyo, Mendoza.

(2011). “Consideraciones sobre los feminismos en América Latina. Producción teórica y prácticas comunicacionales en la Red", en Karina BIDASECA y Vanesa VÁzquez LABA (comps.) Feminismos y Poscolonialidad. Descolonizando el feminismo desde y en América Latina. Buenos Aires: Godot.

FragA, Cristina (2004). "Prólogo", en Agencias de género: comunicadoras en el mundo. Madrid: AMECO.

García, Carmen y Valdivieso, Magdalena (2005). “Una aproximación al Movimiento de Mujeres en América Latina. De los grupos de autoconciencia a las redes nacionales y trasnacionales", en Revista OSAL (Observatorio Social de América Latina), Año VI, núm. 18. 
Gargallo, Francesca (2006). Las ideas feministas latinoamericanas. MéxiCO: UACM.

GIL, Ana Soledad (2012). “La violencia de género en los medios de comunicación. Construcciones de sentido", en Actas III Jornadas Internacionales de Problemas Latinoamericanos. "Movimientos Sociales, Estados y Partidos Políticos en América Latina: $(\mathrm{Re})$ configuraciones institucionales, experiencias de organización y resistencia". Mendoza: UNCuyo.

Gramscl, Antonio (1971). Selección Cuadernos de la cárcel. Nueva York: Quintin Hoare and Geoffrey Nowell (eds.).

Lovera, Sara (2004). "Una agencia de noticias en el tiempo", en Agencias de género: comunicadoras en el mundo. Madrid: AMECO.

RED PAR. Decálogo para el tratamiento periodístico de la violencia contra las mujeres. 2010.

SegAto, Rita (2003). Las estructuras elementales de la violencia. Ensayos sobre género entre la antropología, el psicoanálisis y los derechos humanos. Buenos Aires: Prometeo-UNQ.

unESCO. Indicadores de Género para Medios de Comunicación. Marco de indicadores para evaluar la sensibilidad en materia de género en las operaciones y contenidos mediáticos. Francia: Alton Grizzle 2014.

WACC. Proyecto monitoreo global de medios 2010. ¿Quién figura en las noticias?, septiembre 2010. 